\title{
Non-Thermal Plasma Surface Modification of Biodegradable Polymers
}

\author{
N. De Geyter and R. Morent \\ Research Unit Plasma Technology - Department of Applied Physics, \\ Faculty of Engineering and Architecture - Ghent University, \\ Belgium
}

\section{Introduction}

Biodegradable polymers are often used as packaging materials. However, these polymers can also play an important role in tissue engineering as so called scaffolds (i.e. threedimensional porous structures). The success of these biodegradable scaffolds strongly depends on the reaction of them with their surrounding biological environment. This reaction is mainly governed by the surface features of the scaffold and different approaches have already been tested to change the surface properties of biodegradable polymers. In particular, the research field on the use of non-thermal plasmas for a selective surface modification has known a steep rise. Therefore, this chapter will give an introductory and critical overview on recent achievements in plasma-assisted surface modification of biodegradable polymers. Firstly, we will discuss in short the most commonly biodegradable polymers. Secondly, we will go into more detail about surface modification by a nonthermal plasma and finally we will focus on some examples of plasma-treated biodegradable polymers.

\section{Biodegradable polymers}

\subsection{Biomedical applications}

A biodegradable polymer is defined as a polymer that preserves its mechanical strength and other material performances during its practical application, but that is finally degraded to low molecular weight compounds such as $\mathrm{H}_{2} \mathrm{O}, \mathrm{CO}_{2}$ and other non-toxic byproducts (Ikada \& Tsuji, 2000). Next to their use as packaging material, which is not in the scope of this chapter, biodegradable polymers could play a key role in biomedical engineering for a variety of reasons (Ikada \& Tsuji, 2000). Firstly, since the polymer degrades, it is clear that a device made of such a polymer can be implanted in the human body without necessitating a second surgery to remove the device (Athanasiou et al., 1998, Middleton \& Tipton, 2000). Moreover, this prevented second operation makes the use of biodegradable polymers even more beneficial in other ways. For example, a fractured bone, fixated with a rigid, non-biodegradable stainless steel implant, has an inclination to fracture again when the implant is taken away because during the healing process the bone does not carry sufficient load, since the load is entirely intercepted by the 
rigid steel implant. This is in contrast to a biodegradable implant which degrades little by little and transfers by degrees the load from the implant to the fractured bone. This gradually movement of the load results in less bone re-fracture (Middleton \& Tipton, 2000, Athanasiou et al., 1998).

Secondly, another interesting application field for biodegradable polymers is tissue engineering. This research branch aims to produce completely biocompatible tissues which could be employed to replace damaged or diseased tissues in reconstructive surgery (Djordjevic et al., 2008). Today's focus in this field is the use of so called scaffolds. These scaffolds are 3D artificial matrices that guarantee optimal support and conditions for growth of tissue (Djordjevic et al., 2008). Optimally, these scaffolds should fulfil the following two requirements (Ryu et al., 2005):

- being capable of supporting initial cell growth and further proliferation

- having the ability to degrade over time while leaving behind a reproduced functional tissue.

Finally, biodegradable polymers can also contribute in controlled drug delivery (Amass et al., 1998). A gradual delivery of antibiotics can be beneficial for the treatment of deep skeletal infections after a surgery, while the healing process of a fractured bone can be enhanced by a delivery in stages of bone morphogenetic proteins (Agrawal et al., 1995, Wang et al., 1990, Ramchandani \& Robinson, 1998).

\subsection{Overview of the most commonly used biodegradable polymers}

Both natural and synthetic polymers have been extensively studied as biodegradable biomaterials (Nair \& Laurencin, 2007). At first, natural polymers were considered as promising candidates. Nevertheless, several studies quickly demonstrated that some of these materials involve different drawbacks: possibility of disease transmission, strong immunogenic reactions and major difficulties with the purification process (Nair \& Laurencin, 2007). In a later stage, synthetic biodegradable polymers were developed by the synthesis of polymers with hydrostatically unstable linkages in their backbones (Middleton \& Tipton, 2000). These hydrostatically unstable groups are esters, ortho-esters, anhydrides and amines (Middleton \& Tipton, 2000). The major advantages of synthetic over natural polymers are (Nair \& Laurencin, 2007):

- $\quad$ synthetic biodegradable polymers are biologically inert

- they have more predictable properties

- their characteristics can be tailored with a specific application in mind

Various synthetic biodegradable polymers were invented of which the aliphatic polyesters appear to be the most attractive for biomedical applications. For this reason, this chapter will only discuss this type of polymers. An aliphatic polyester is a thermoplastic polymer which contains hydrolysable aliphatic ester linkage in its backbone (Donglu, 2010). In theory all polyesters are degradable, however only aliphatic polyesters with reasonably short aliphatic chains between the ester bonds will degrade within a time interval suitable for biomedical applications (Nair \& Laurencin, 2007). Such aliphatic polyesters can be derived from a wide range of monomers through ring-opening and condensation polymerisation routes, but in some cases bacterial processes can also be used. In what follows we will briefly discuss the most common biodegradable aliphatic polyesters. The structural chemical formula of each discussed polymer is given in Table 1. 


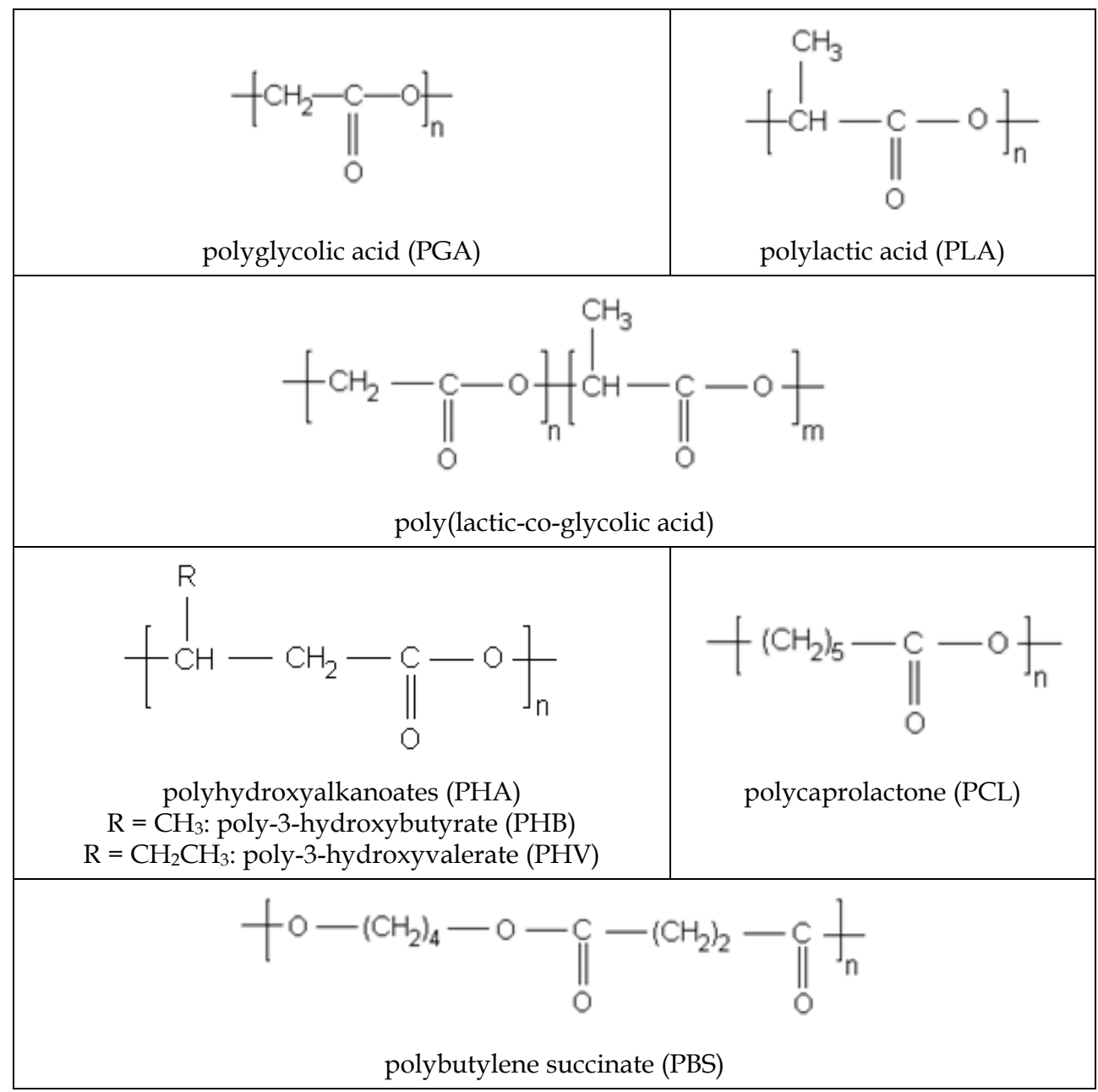

Table 1. Structural chemical formula of the most common biodegradable polymers.

\subsubsection{Polyglycolic acid (PGA)}

Polyglycolic acid (PGA) or polygycolide is the most simple linear biodegradable polymer and known as a rigid thermoplastic polymer (Vroman \& Tighzert, 2009). Due to its high crystallinity (44-55\%) PGA provides excellent mechanical properties and it exhibits a low solubility in most organic solvents. Alow solubility (Nair \& Laurencin, 2007). Nevertheless, it is soluble in highly-fluorinated solvents, such as hexafluoroisopropanol (Donglu, 2010). PGA has initially been studied for use as resorbable synthetic sutures and was for the first time commercialised in 1962 under the name DEXON ${ }^{\circledR}$ (Gilding \& Reed, 1979). Today, due to their excellent biodegradability, good cell viability and good initial properties, PGA nonwoven fabrics are also extensively utilized as scaffolds for tissue engineering (Nair \& Laurencin, 2007). 
PGA loses its strength in 1 to 2 months when hydrolyzed and its mass within 6 to 12 months (Nair \& Laurencin, 2007). When inserted in the body, PGA breaks down into glycolic acid. Glycolic acid is not toxic and can be excreted in the urine or converted into $\mathrm{H}_{2} \mathrm{O}$ and $\mathrm{CO}_{2}$ and subsequently removed from the body via the respiratory system (Maurus \& Kaeding, 2004). Despite the above-mentioned non-toxicity of glycolic acid, it may result in an increased and localized acid concentration leading to tissue dammage (Gunatillake \& Adhikari, 2003, Taylor et al., 1994). This presents in particular problems for orthopaedic applications where implants with substantial dimensions are needed (Gunatillake \& Adhikari, 2003). Together with the high degradation rate and low solubility, these acidic degradation products have hampered the use of PGA for biomedical engineering applications.

\subsubsection{Polylactic acid (PLA)}

The monomer building block of polylactic acid, lactic acid, is formed by converting sugar or starch from vegetable origin (e.g. wheat, corn, rice, etc.) via either bacterial fermentation or via a petrochemical process (Rasal et al., 2010). If PLA is implanted, it hydrolyses to its building block lactic acid which is a normal human metabolic by-product (Gunatillake \& Adhikari, 2003). Lactic acid is degraded into $\mathrm{H}_{2} \mathrm{O}$ and $\mathrm{CO}_{2}$ which can be further removed by the respiratory system (Nair \& Laurencin, 2007, Maurus \& Kaeding, 2004). As can be seen in Table 1, lactic acid is a chiral molecule and therefore different forms of PLA occur. The two most important forms are poly(L-lactic acid) (PLLA) and poly(DL-lactic acid) (PDLLA).

Similar to PGA, PLLA has a high degree of crystallinity $( \pm 37 \%$ depending on molecular weight and production processes) (Nair \& Laurencin, 2007). Compared to PGA, PLLA slowly degrades: when PLLA is hydrolyzed, it loses its strength in circa 6 months. However, no mass loss is observed for a very long time and total degradation amount up to several years (Middleton \& Tipton, 2000, Nair \& Laurencin, 2007, Bergsma et al., 1995). Next to this slow degradation, PLLA offers good tensile strength, a high tensile modulus and low extension and can therefore be applied in load bearing applications like in orthopaedic fixation devices (Nair \& Laurencin, 2007). PLLA fibres are also often used as surgical sutures, while PLLA composites, porous membranes or sponges can be employed as scaffolding matrices for tissue regeneration (Hu \& Huang, 2010, Heino et al., 1996, Lam et al., 1995, Vaquette et al., 2008, Ma et al., 2006, Chen \& Ma, 2004). For some other applications, the long degradation time of PLLA however presents a major concern.

PDLLA has an amorphous nature resulting in a substantial lower strength compared to PLLA (Nair \& Laurencin, 2007). Moreover, PDLLA loses its strength in 1 to 2 months and its mass within 12 to 16 months (Maurus \& Kaeding, 2004). Taking into account this low strength and its fast degradation rate, PDLLA can be employed as drug delivery system or as low strength scaffolding matrix for tissue engineering (Nair \& Laurencin, 2007, Xie \& Buschle-Diller, 2010).

\subsubsection{Poly(lactic-co-glycolic acid) (PLGA)}

A lot of research has been carried out on the development of a full range of poly(lactic-coglycolic acid) (PLGA) polymers. This research has indicated that the degradation rate of PLGA strongly depends on the lactic acid/glycolic acid ratio (Gilding \& Reed, 1979, Reed \& Gilding, 1981, Miller et al., 1977). It is common knowledge that the intermediate co-polymers are much more unstable than the homo-polymers: a 50/50 PLGA and an 85/15 PLGA degrade in 1-2 months and 5-6 months respectively (Middleton \& Tipton, 2000). This opportunity to tune the degradation rate of the polymer by varying the monomer ratio has made PLGA an ideal 
candidate for biomedical applications in the drug delivery and tissue engineering domain. However, the first commercial use of the co-polymer PLGA was as suture material under the name Vicryl ${ }^{\circledR}($ Nair \& Laurencin, 2007, Gunatillake \& Adhikari, 2003).

\subsubsection{Polycaprolactone (PCL)}

Polycaprolactone (PCL) is of great interest since it can be obtained from the relatively cheap monomer unit $\varepsilon$-caprolactone (Storey \& Taylor, 1998). PCL degrades very slowly and complete degradation can take several years. Due to this slow degradation, its non-toxicity and its high permeability to small drug molecules, PCL has in the beginning been studied as a polymer for long-term drug delivery systems. PCL also offers excellent biocompatibility. Therefore, recently extensive research has been done on the use of PCL as scaffold matrices in tissue regeneration (Chiari et al., 2006, Mondrinos et al., 2006). Also several co-polymers have been developed to increase the degradation rate compared to pure PCL ( $\mathrm{Li}$ et al., 2002, Li et al., 2003, Qian et al., 2000, Wang et al., 2001). For co-polymers synthesized from Llactide and $\varepsilon$-caprolactone, the degradation rate was again strongly influenced by the Llactide/ $\varepsilon$-caprolactone ratio.

\subsubsection{Polyhydroxyalkanoates (PHA)}

Polyhydroxyalkanoates (PHA) are structurally related to PLA and are a polyester class derived from hydroxyalkanoic acids which can vary in chain length and in the hydroxyl group positions (Breulmann et al., 2009). As is the case for PLA, PHA can be obtained from renewable resources like starch, sugars or fatty acids, however, chemical transformation is not needed. The most widespread PHA is poly-3-hydroxybutyrate (PHB) which was discovered in 1920 as produced by the bacteria "Bacillus megaterium" (Nair \& Laurencin, 2007). Subsequent research showed that PHB could also be synthesized via other bacterial strains and via chemical routes. Subsequent research showed that PHB could also be synthesized via other bacterial strains and via chemical routes (Shelton et al., 1971).

PHB degrades into D-3-hydroxybutyrate which is a normal element of human blood (Wang et al., 2001). To be used directly as biopolymer, PHB has the disadvantage of a very low degradation rate in the body compared with other biodegradable polyesters and is often considered too brittle for many applications (Nair \& Laurencin, 2007, Pompe et al., 2007). Therefore, co-polymers of 3-hydroxybutyrate with other monomers such as 3-hydroxyvalerate have been synthesized (Nair \& Laurencin, 2007). This poly(3-hydroxybutyrate-co-3hydroxyvalerate) (PHBV) is far less brittle and thus offers more potential as biomaterial (Nair \& Laurencin, 2007, Ojumu et al., 2004). Moreover, PHBV is piezoelectric which enables electrical stimulation - known for promoting bone healing - of the implant (Nair \& Laurencin, 2007). Although the faster degradation rate of PHBV compared to PHB, it has been observed that the in vivo degradation of both polymers remains slow. Therefore, these polymers may be potential candidates for long term implants.

\subsubsection{Polybutylene succinate (PBS)}

Polybutylene succinate (PBS) was discovered in 1990 and commercialized under the trade name Bionolle ${ }^{\circledR}$ (Fujimaki, 1998). PBS degrades via naturally occurring enzymes and microorganisms into $\mathrm{H}_{2} \mathrm{O}$ and $\mathrm{CO}_{2}$ (Tserki et al., 2006). PBS can be easily produced in a wide variety of forms and structures, such as yarns, non-wovens, films, mono-filaments and it 
offers excellent mechanical properties comparable with polyethylene or polypropylene (Li et al., 2005, Vroman \& Tighzert, 2009). These characteristics makes PBS an excellent choice for use as scaffolds in tissue regeneration.

\section{Plasma-assisted surface modification of biodegradable polyesters}

\subsection{Introduction}

Biodegradable polymers are non-toxic, possess low immunogenicity and good mechanical properties. Moreover, their degradation rate can be adjusted and therefore recently they have been extensively studied as scaffold matrices for tissue engineering (Shen et al., 2007). This research indicated that due to their hydrophobicity and their low surface energy cells only poorly attach, spread and proliferate on these biodegradable polyesters. Therefore, the surface of these polyesters should usually be modified and already several approaches have been presented to increase their cell affinity (Desmet et al., 2009). Typically the polyesters are chemically modified by introducing specific functional groups on their surface. Two possible wet-chemical routes are surface aminolysis and surface hydrolysis. Surface aminolysis in for example 1,6-hexanediamine leads to the production of free amino groups on the surface of the polyester which improves cell adhesion (Zhu et al., 2002, Zhu et al., 2004). By applying surface hydrolysis with the use of a $\mathrm{NaOH}$ solution, the ester group is hydrolyzed by the hydroxide anion leading to a rupture of the polymer chain and the formation of carboxylic acid and hydroxyl groups on the tail ends of the two new chains.

The presence of these groups results in an enhanced hydrophilicity and in improved cellmaterial interactions (Zhu et al., 2002, Zhu et al., 2004). Although these wet-chemical processes have their merit, some disadvantages cannot be neglected. Such surface modifications are quite rough and can thus possibly lead to unwanted side-effects such as a faster degradation rate and a reduction of mechanical performance (Chong et al., 2007, Desmet et al., 2009). In addition, research indicated that these techniques can lead to irregular surface etching and that the degree of modification strongly depends on molecular weight, crystallinity or tacticity and may therefore not be reproducible (Goddard \& Hotchkiss, 2007, Desai \& Singh, 2004). Moreover, it is clear that these wet-chemical techniques use substantial amounts of water or other liquids and consequentially generate hazardous chemical waste. Other approaches like peroxide oxidation, ozone oxidation, UV- and $\gamma$-radiaton can also introduce reactive chemical groups on the polyester surface, however, most of these techniques also lead to degradation of the polyesters (Ho et al., 2007, Koo \& Jang, 2008, Loo et al., 2004, Place et al., 2009, Montanari et al., 1998).

Opposite those above-mentioned techniques, plasma-assisted surface modification offers a very suitable strategy to incorporate reactive functional groups on the polyester surface. Without the use of a solvent, these groups are efficiently introduced on the surface without altering the bulk properties of the polymer (Ho et al., 2006, Desmet et al., 2009). In addition, complex shaped scaffolds can be uniformly treated (Shen et al., 2007). Next to the incorporation of functional groups, plasma treatment can also be employed for the deposition of polymer coatings or for the immobilization of proteins or other biomolecules (Yang et al., 2002, Cheng \& Teoh, 2004, Barry et al., 2005, Barry et al., 2006, Guerrouani et al., 2007, Zelzer et al., 2009).

Due to these numerous advantages, surface modification of biodegradable polymers by plasma treatment offers several excellent prospects. Therefore, in this section 3 , we will give 
a more general introduction on plasma-surface interactions, while in section 4 we will focus on some successful examples of plasma modification of biodegradable aliphatic polyesters.

\subsection{Plasma-surface interactions and surface modification strategies}

Plasma is sometimes referred to as the fourth state of matter as introduced by Langmuir (Langmuir, 1928). Plasma is a partly ionized, but quasi-neutral gas in the form of gaseous or fluid-like mixtures of free electrons, ions and radicals, generally also containing neutral particles (atoms, molecules) (Denes \& Manolache, 2004). Some of these particles may be excited and can return to their ground state by emission of a photon. The latter process is at least partially responsible for the luminosity of a typical plasma. In plasma several electrons are not bound to molecules or atoms, but free. Therefore, positive and negative charges can move somewhat independently from each other.

Plasmas are frequently subdivided into equilibrium (or non-thermal/lowtemperature/cold) and non-equilibrium (or thermal/high-temperature/hot) plasmas (Denes \& Manolache, 2004, Bogaerts et al., 2002, Fridman et al., 2008). Thermal equilibrium implies that the temperature of all particles (electrons, ions, neutrals and excited species) is the same. This is, for example true for stars, as well as for fusion plasmas. High temperatures are required to form these type of plasmas (Bogaerts et al., 2002, Lieberman \& Lichtenberg, 2005). In contrast, plasmas with strong deflection from kinetic equilibrium have electron temperatures that are a lot more elevated than the temperature of the ions and neutrals. Such plasmas are classified as non-equilibrium or non-thermal plasmas. It is clear that the high temperatures used in thermal plasmas are destructive for heat-sensitive polymers and most applications for surface modification of polymers will make use of nonthermal or cold plasmas. Since a non-thermal plasma contains a mixture of reactive species, different interactions between the plasma and a surface are possible, including plasma treatment, plasma polymerization and plasma etching (Denes \& Manolache, 2004, Rausher et al., 2010, Gomathi et al., 2008). These different interactions between a plasma and the surface can be divided into 4 different approaches to modify the biodegradable polymer. These 4 approaches will briefly be introduced in the following paragraphs, while section 4 will give some practical examples.

\subsubsection{Plasma treatment}

Plasma treatment is mostly used to enhance the surface energy of a polymer. Figure 1 shows the decrease in contact angle of a PLA surface after treatment in different discharge atmospheres. Oxygen or nitrogen containing groups are introduced on the surface of a (biodegradable) polymer when the material is exposed to a cold plasma generated in $\mathrm{O}_{2}, \mathrm{~N}_{2}$, air or $\mathrm{NH}_{3}$ (Morent et al., 2008a, Morent et al., 2008b). These functionalities are polar hydrophilic groups which are formed during the interaction of the plasma active species with the polymer molecules. Next to oxygen- and nitrogen-containing discharges, plasmas generated in pure helium or argon will lead to the creation of free radicals that can be used for cross-linking or grafting of oxygen-containing groups when the surface is exposed to oxygen or air after the treatment (Desmet et al., 2009, De Geyter et al., 2007, Ding et al., 2004). Finally, it should be mentioned that the induced surface characteristics are not permanent. The treated surfaces will tend to partially recover to their untreated state during storage in e.g. air (so-called hydrophobic recovery) and they will also undergo post-plasma oxidation reactions (De Geyter et al., 2008, Morent et al., 2010, Siow et al., 2006). 


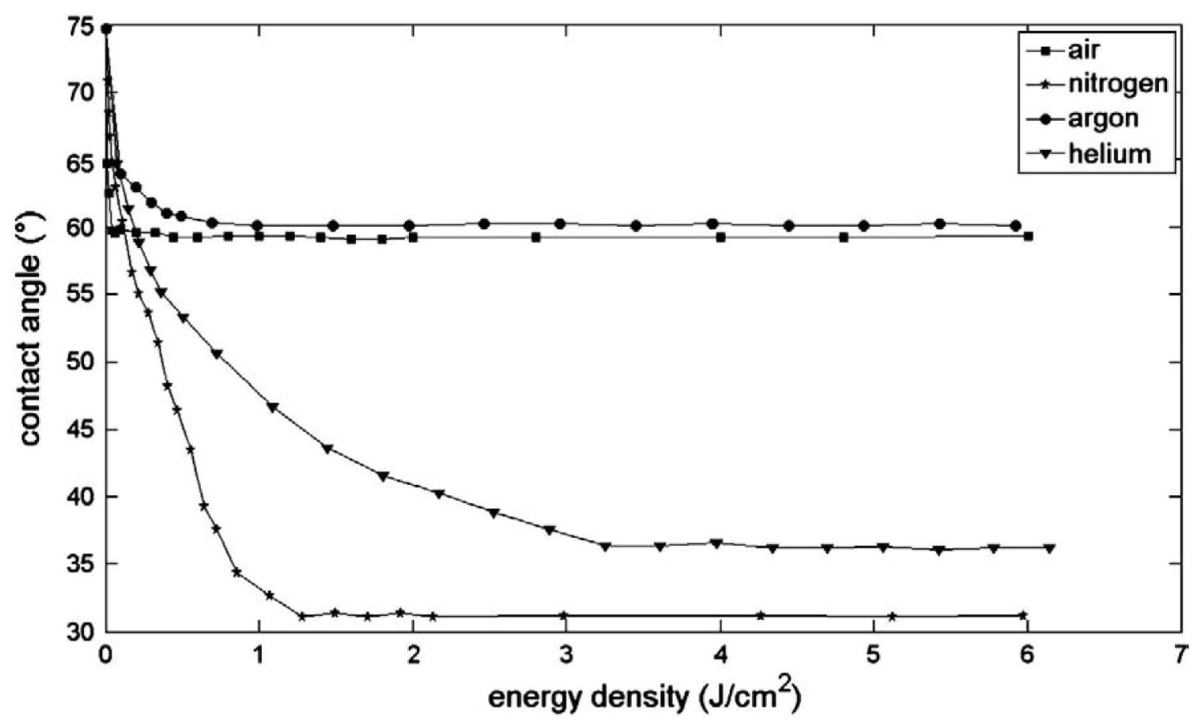

Fig. 1. Water contact angles as a function of energy density for air, nitrogen, argon and helium plasma-treated PLA samples. (Reprinted from (De Geyter et al., 2010) with permission of Elsevier).

\subsubsection{Plasma post-irradiation grafting}

Plasma post-irradiation grafting is a two-step process of which the first step is a plasma treatment as described in the previous paragraph. The induced functionalities can then be applied to initiate polymerization reactions (Desmet et al., 2009). In contrast to plasma treatment, this technique results in a permanent effect. In the second step, the activated polymer surface is brought into direct contact with a monomer. The monomer can be in the gas phase or the substrate can be immersed into a monomer solution (Vasilets et al., 1997, Zhu et al., 2007). It is important to notice that in both cases the monomer is not subject to the reactive plasma environment. Therefore, the grafted polymers will have similar characteristics as polymers synthesized by conventional polymerization processes (Desmet et al., 2009).

\subsubsection{Plasma syn-irradiation}

Firstly, a monomer is adsorbed to a material, after which the substrate is exposed to a plasma (Ding et al., 2004). This plasma will generate radicals in the adsorbed monomer layer and the surface of the substrate. This approach will lead to a cross-linked polymer top-layer (Desmet et al., 2009). Opposite to the plasma post-irradiation grafting described in the previous paragraph, the monomer is in plasma syn-irradiation directly subjected to the plasma.

\subsubsection{Plasma polymerization}

Thin films with unique chemical and physical properties can be developed by plasma polymerization and are called plasma polymers (Gomathi et al., 2008). During plasma 
polymerization, gaseous or liquid monomers are typically via a carrier gas inserted into the discharge zone in which they are converted into reactive fragments (Morent et al., 2009). These reactive fragments recombine to polymers and a polymer film is deposited on the substrate exposed to the plasma. The formed plasma polymers will not necessarily have the same chemical structure and composition as polymers obtained via conventional polymerization processes (Desmet et al., 2009). In general, plasma polymers are pinhole-free and highly cross-linked and are therefore insoluble, thermally stable, chemically inert and mechanically tough. Furthermore, such films are often highly coherent and adherent to a variety of substrates including conventional polymer, glass and metal surfaces (Morent et al., 2011, Morent et al., 2009).

\section{Examples of plasma-assisted surface modification of biodegradable polyesters}

In this last section, we will give some examples of the above-mentioned approaches of plasma-assisted surface modification of biodegradable aliphatic polyesters. Due to the introductory nature of this chapter, not all literature will be discussed in detail. For a more complete overview of literature, the reader could consult the review paper on the same subject of our research group (Morent et al., 2011). Plasma treatment as described in section 3.2.1 is by far the most occurring approach used to modify the surface of biodegradable polyesters and numerous examples can be found in literature. In this chapter, we will try to give some examples for all the biodegradable polyesters discussed in section 2 . Therefore, section 4.1 will be much more extensive than the other sections (4.2 up to 4.4) since the availability of literature on these latter approaches is less pronounced.

\subsection{Plasma treatment of biodegradable polymers}

Hirotsu et al. published in 1997 one of the first studies on plasma modification of biodegradable polymers and treated PLA fabrics with a low pressure radio frequent (RF) discharge generated in pure oxygen and nitrogen (Hirotsu et al., 1997). The same group reported in 2002 about an enhancement of the wettability of PLLA sheets and showed a strong decrease in water contact angle from $80^{\circ}$ to approximately $55^{\circ}$ after 30 seconds of oxygen and helium plasma treatment (Hirotsu et al., 2002). They suggested that this increased wettability was only due to chemical changes of the surface, since pronounced etching is not likely to happen after such short treatment times. However, they were not able to determine the groups incorporated at the surface.

\begin{tabular}{c|ccc} 
& $\begin{array}{c}\mathrm{C} \\
(\text { at\% })\end{array}$ & $\begin{array}{c}\mathrm{O} \\
(\text { at\% })\end{array}$ & $\begin{array}{c}\mathrm{N} \\
(\text { at\% })\end{array}$ \\
\hline $\begin{array}{c}\text { no treatment } \\
\text { air plasma treatment }\end{array}$ & 68 & 32 & 0 \\
& 62 & 38 & 0
\end{tabular}

Table 2. Atomic composition of untreated and air plasma-treated PLA films (De Geyter et al., 2010).

To identify the functionalities incorporated at the surface, De Geyter et al. did detailed XPS studies on PLA sheets plasma-treated with a medium pressure dielectric barrier discharge (DBD) sustained in air. Table 2 shows the atomic composition of the PLA films plasma- 
treated in air. This table suggests that air plasma mainly adds oxygen atoms to the PLA surfaces. From high-resolution XPS scans, the authors have concluded that after plasma treatment in air, the concentration of $\mathrm{C}-\mathrm{O}$ and $\mathrm{O}-\mathrm{C}=\mathrm{O}$ groups increases, while the $\mathrm{C}-\mathrm{C}$ and $\mathrm{C}-\mathrm{H}$ functional groups decrease. Hirtosu et al. observed a gradual increase in water contact angle when PLA samples were kept in dry air (Hirotsu et al., 2002). A similar hydrophobic recovery has recently been examined in detail by Morent et al., who employed a medium pressure DBD in different atmospheres for the surface modification of PLA. They concluded that during storage in air, the induced polar chemical groups reorientate or migrate to the bulk of the material (Morent et al., 2010). The introduction of specific functional groups on the surface of PLA samples and the accompanying increase in wettability often have the aim to improve the cell-material interactions. These interactions between B65 nervous tissue cells and oxygen plasma-treated PLLA films were studied by Khorasani et al. (Khorasani et al., 2008). Figure 2 shows optical photomicrographs of B65 cell attachment and growth on untreated and plasma-modified PLLA surfaces and it can clearly be observed that this oxygen plasma treatment substantially improves cell attachment and growth. The authors concluded that plasma-modified PLLA surfaces are very suitable for nervous tissue engineering purposes.

The majority of the above-discussed research is on flat 2D PLLA surfaces. However, from biomedical point of view, 3D porous polymer scaffolds are needed in the field of tissue engineering in order to offer sufficient support for tissue growth (Djordjevic et al., 2008). Only few authors have worked with 3D structures because of two reasons: (1) the insufficient knowledge on the penetration of plasma into porous structures and (2) the difficulty of characterisation of the interior surface with classical surface analytical tools. Wan et al. have modified $4 \mathrm{~mm}$ thick PLLA scaffolds with an ammonia plasma (Wan et al., 2006). To examine the plasma effect, they have immersed the scaffolds in blue ink after treatment to demonstrate the influence of treatment time on the modifying depth. Figure 3 shows that due to the poor hydrophilicity of the internal surface of the untreated PLLA sample only the most outside layer is dyed. However, with increasing treatment time, the ink increasingly penetrates the PLLA scaffold and after a treatment of half an hour the interior part of the scaffold is fully dyed.

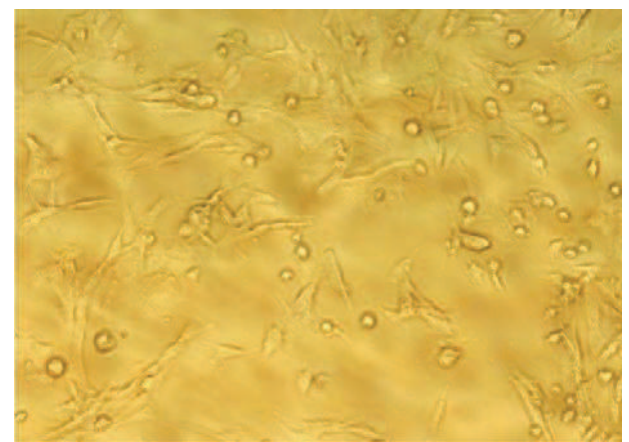

(a)

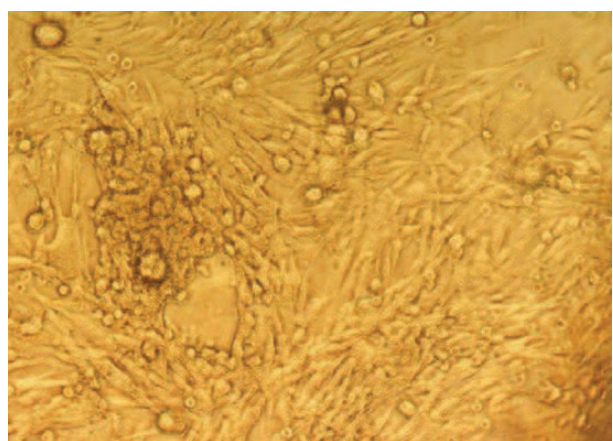

(b)

Fig. 2. B65 attachment on (a) untreated PLLA and (b) oxygen plasma-treated PLLA (magnification 400x) (Reprinted from (Khorasani et al., 2008) with permission of Elsevier). 


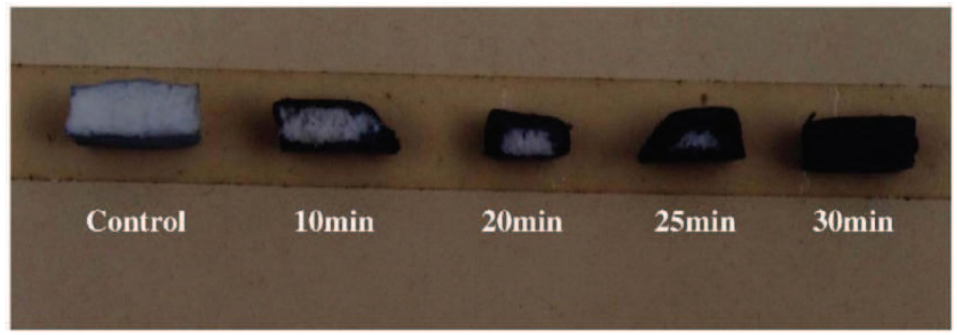

Fig. 3. Effect of plasma treatment time on the modifying depth of PLLA scaffolds (Reprinted from (Wan et al., 2006) with permission of Elsevier).

To our knowledge, no literature on plasma treatment of polyglycolic acid has been published so far. However, quite a few research articles deal with plasma modification of the copolymer PLGA (Khorasani et al., 2008, Hasirci et al., 2010, Khang et al., 2002, Park et al., 2007, Park et al., 2010, Safinia et al., 2007, Safinia et al., 2008, Shen et al., 2008, Wang et al., 2004). 50/50 PLGA films were modified in an oxygen plasma at low pressure and a decrease of the contact angle from $67^{\circ}$ to below $40^{\circ}$ after plasma treatment was observed. XPS revealed that oxygen containing functionalities are introduced and cell culture tests (3T3 fibroblasts) showed a higher cell attachment and proliferation on oxygen plasma-treated PLGA surfaces. As discussed in the previous paragraph on PLLA treated surfaces, Khorasani et al. also investigated in the same paper the interaction between nervous tissue cells and plasma modified PLGA samples (Khorasani et al., 2008). Figure 4 shows that oxygen plasma treatment clearly improves attachment and growth of B65 cells, however, the effect of oxygen plasma treatment seems less pronounced as was the case for PLLA surfaces (see Figure 2). Khang et al. studied and compared several modification methods including chemical methods (sulphuric acid, chloric acid, sodium hydroxide) as well as physical methods (atmospheric pressure air discharge) for the surface treatment of PLGA (Khang et al., 2002). Their results clearly evidenced that both chemical methods and plasma treatment could enhance cell attachment and growth. The high potential of non-thermal plasma for the surface modification of biodegradable polymers was clearly demonstrated since plasma treatment showed to be almost as efficient in increasing cell-material interactions as a chloric acid treatment and more efficient than sulphuric acid and sodium hydroxide treatments.

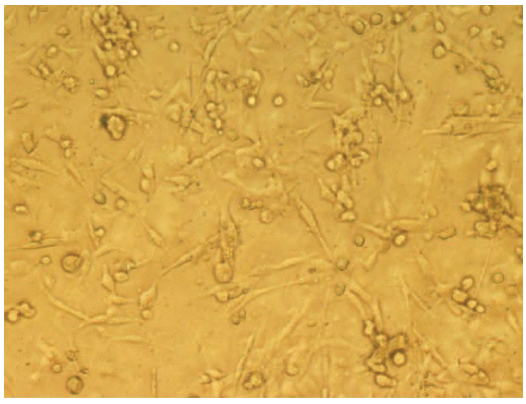

(a)

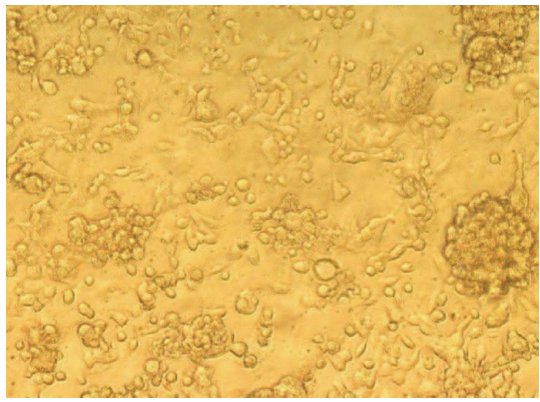

(b)

Fig. 4. B65 cell attachment on (a) untreated PLGA and (b) oxygen plasma-treated PLGA (magnification 400x) (Reprinted from (Khorasani et al., 2008) with permission of Elsevier). 
Surface modification of PCL with oxygen, helium and air plasmas has resulted into similar effects as on PLA and PLGA: an increased hydrophilicity, a higher oxygen amount and consequently an enhanced cell attachment and proliferation (Yildirim et al., 2008, Hirotsu et al., 2000a, Lee et al., 2009, Prabhakaran et al., 2008, Little et al., 2009). Lee and co-workers treated PCL with atmospheric pressure plasmas with different discharge gases (Lee et al., 2008). Figure 5 shows the enhancement in hydrophilicity (Figure 5 (a)), the increased cell attachment (Figure 5 (b)) and the increased cell proliferation (Figure 5 (c)).

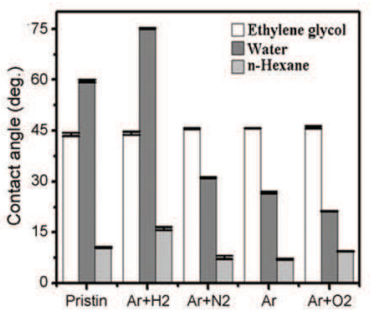

(a)

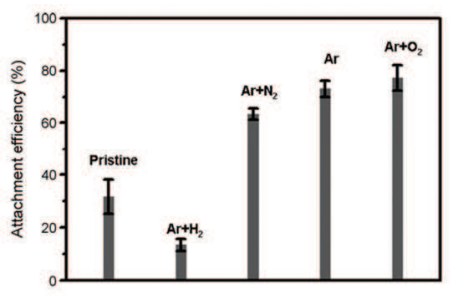

(b)

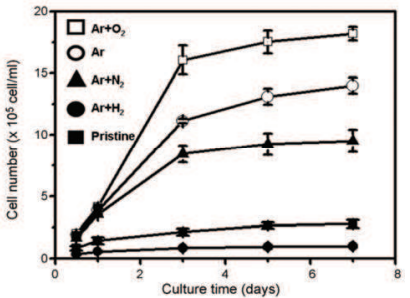

(c)

Fig. 5. Plasma treatment of PCL: (a) contact angle (b) cell attachment and (c) cell proliferation of human epithelial cells (Reprinted from (Lee et al., 2008) with permission of Elsevier).

The most common polyhydroxyalkanoate subjected to plasma treatments is the co-polymer poly(3-hydroxybutyrate-co-3-hydroxyvalerate) (PHBV) and oxygen plasmas have been widely employed to modify this co-polymer (Wang et al., 2006, Hasirci et al., 2003, Tezcaner et al., 2003, Kose et al., 2003b, Kose et al., 2003a, Ferreira et al., 2009). A low pressure oxygen plasma was employed to PHBV films containing $8 \%$ hydroxyvalerate in its structure by Hasirci et al. (Hasirci et al., 2003). A decrease in water contact angle upon oxygen plasma treatment was observed which was attributed to the incorporation of oxygen-containing functional groups on the PHBV surface. A subsequent study showed that $\mathrm{O}_{2}$ plasma treatment significantly enhanced the interaction between retinal pigment epithelium (RPE) cells and PHBV (Tezcaner et al., 2003).

Hirotsu et al. published an interesting article on the plasma modification of self-made PBS sheets in different discharge atmospheres $\left(\mathrm{O}_{2}, \mathrm{~N}_{2}\right.$ and helium) (Hirotsu et al., 2000b). Contact angle measurements on the plasma-modified samples clearly showed that plasmas are able to increase the hydrophilicity, however, it was not stated which chemical groups contributed to this increased wettability.

\subsection{Plasma post-irradiation grafting of biodegradable polyesters}

Section 4.1 clearly focussed on the observation that plasma treatment can easily induce desired functionalities onto the surface of biodegradable polymers resulting in an improved cell affinity. However, hydrophobic recovery acts as a brake on practical applications of plasma-treated polyesters. Nevertheless, this drawback can be solved by covalently immobilizing bioactive molecules on plasma-treated surfaces (Gupta et al., 2002). Typically extracellular matrix (ECM) proteins such as gelatine, collagen or fibrin have been grafted on the surface of biodegradable polyesters since these proteins are known to enhance cell adhesion and proliferation (Ma et al., 2007). Different authors have studied the immobilization of collagen on PCL films (Ma et al., 2007, Chong et al., 2007, 
Cheng \& Teoh, 2004). Firstly, an argon plasma is applied to a PCL film to generate radicals on the polyester surface. Exposure to the atmosphere for several minutes leads to the formation of functionalities such as surface peroxides and hydroperoxides that will be employed as initiator sites for UV-induced graft polymerization of acrylic acid. To preactivate the carboxyl groups, the grafted substrates are immersed into a carbodiimide solution. In a final step, the material is immersed into a collagen solution leading to the production of a collagen-immobilized biodegradable polyester. These collagen-modified PCL surfaces have been tested with a diversity of cells including human dermal fibroblasts, human myoblasts, human endothelial cells and human smooth muscle cells and all demonstrated favourable response from these cells (Ma et al., 2007, Chong et al., 2007, Cheng \& Teoh, 2004). Next to collagen, Kang et al. also immobilized insulin on the surface of a PHBV co-polymer and observed that the proliferation of human fibroblasts was significantly accelerated on these films compared to the untreated samples (Kang et al., 2001).

\subsection{Plasma syn-irradiation of biodegradable polyesters}

As described in section 3.2.3, a polymer can also be grafted on the surface of a biodegradable polyester by pre-adsorption of the monomer followed by a plasma treatment. However for the specific case of biodegradable polymers, we were able to track only one research paper using this plasma approach (Ding et al., 2004). In this paper, Ding et al. tried to modify the surface of PLLA films with a chitosan layer. However, results indicated poor cell adhesion, but acceptable cell proliferation.

\subsection{Plasma polymerization on biodegradable polyesters}

Plasma polymerization differs from plasma grafting in that respect that it coats the substrate rather than covalently binds species to a plasma-modified polymer surface (Barry et al., 2005). Allylamine is one of the most frequently used monomers to plasma polymerize on biodegradable polymers such as PLLA, PCL and PHBV (Barry et al., 2005, Guerrouani et al., 2007, Carlisle et al., 2000). Plasma polymerized allylamine films on biodegradable polymers resulted in highly hydrophilic surfaces with contact angles of $20^{\circ}$ or lower due to the amine groups on the surface.

As there is a great interest in the surface modification of 3D implants, plasma polymerization has also been performed on the surface of 3D PLA scaffolds. Plasma grafting has been compared with plasma polymerization using allylamine (Barry et al., 2005). In the case of plasma grafting, the scaffolds were first pre-treated with an oxygen plasma and afterwards exposed to allylamine vapour, while plasma polymerization was carried out by exposing the scaffolds to an allylamine vapour plasma after an oxygen plasma pretreatment. XPS measurements of the scaffolds at different points across the scaffold diameter demonstrated that the grafting process resulted in a more homogeneous nitrogen concentration through the scaffold while the concentration of nitrogen on the internal surface of the scaffold on which the plasma deposit was formed decreased from the edge to the core of the scaffold, as can be seen in Figure 6. However, at the lowest nitrogen concentration, the nitrogen concentration on the internal surface of the plasma-polymerized scaffold was still greater than that of the grafted surface. The plasma-coated scaffolds also showed a higher metabolic activity than the plasma-grafted samples. Moreover, fibroblasts 
were detected in the centre of the plasma-coated samples, which was not the case for the grafted scaffolds (Barry et al., 2005).

\section{Conclusion}

The growing research fields of tissue engineering and regenerative medicine are a leverage for surface engineering of biodegradable polymers. Next to chemical surface modification techniques which encounter problems with the use of hazardous organic solvents in relation to cell viability, non-thermal plasma technology knows a steep growth as solvent-free technique. Plasma treatments are already commonly performed on biodegradable polymers such as PLA and PLGA, while treatment of more advanced biodegradable polymers (such as PCL, PHBV, PBS and composites) and other plasma-based techniques (such as plasma grafting and plasma polymerization) are only at the verge of breaking through. Nonthermal plasma technology can greatly enhance cell-material interactions, however, a better understanding of these interactions is of crucial importance. This knowledge can provide us information on which plasma-based strategies should exactly be pursued.

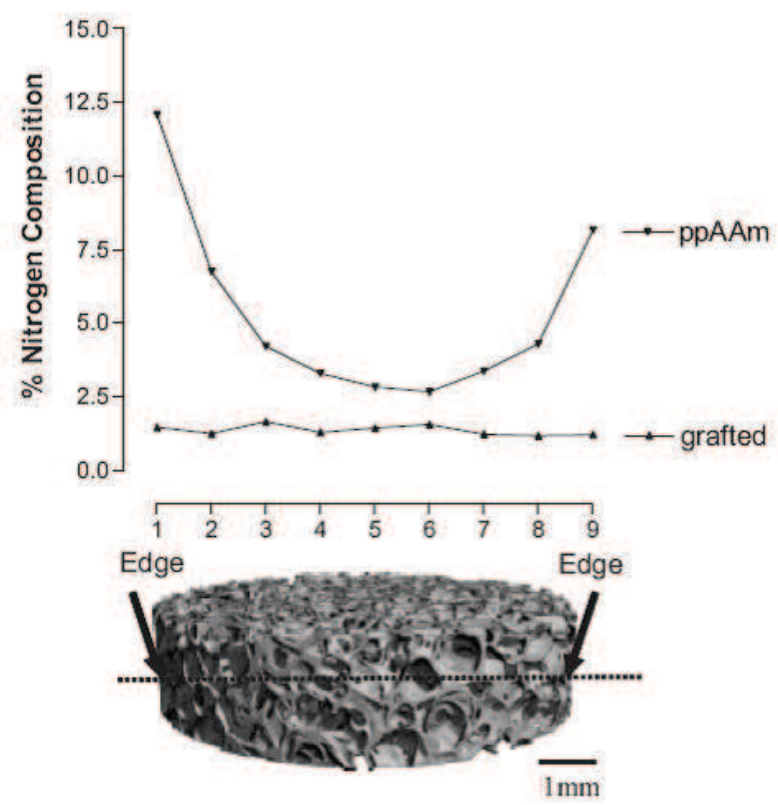

Fig. 6. Nitrogen concentration as determined by XPS at set points across the internal diameter of grafted and plasma-polymerized allylamine (ppAAm) scaffolds (Reprinted from (Barry et al., 2005) with permission from Wiley-VCH Verlag GmbH \& Co. KGaA).

\section{References}

Agrawal, C. M., Best, J., Heckman, J. D. \& Boyan, B. D. 1995. Protein Release Kinetics of A Biodegradable Implant for Fracture Non-Unions. Biomaterials, 16, 1255-1260. 
Amass, W., Amass, A. \& Tighe, B. 1998. A review of biodegradable polymers: Uses, current developments in the synthesis and characterization of biodegradable polyesters, blends of biodegradable polymers and recent advances in biodegradation studies. Polymer International, 47, 89-144.

Athanasiou, K. A., Agrawal, C. M., Barber, F. A. \& Burkhart, S. S. 1998. Orthopaedic applications for PLA-PGA biodegradable polymers. Arthroscopy-the Journal of Arthroscopic and Related Surgery, 14, 726-737.

Barry, J. J. A., Howard, D., Shakesheff, K. M., Howdle, S. M. \& Alexander, M. R. 2006. Using a core-sheath distribution of surface chemistry through 3D tissue engineering scaffolds to control cell ingress. Advanced Materials, 18, 1406-+.

Barry, J. J. A., Silva, M. M. C. G., Shakesheff, K. M., Howdle, S. M. \& Alexander, M. R. 2005. Using plasma deposits to promote cell population of the porous interior of threedimensional poly(D,L-lactic acid) tissue-engineering scaffolds. Advanced Functional Materials, 15, 1134-1140.

Bergsma, J. E., Rozema, F. R., Bos, R. R. M., Boering, G., Debruijn, W. C. \& Pennings, A. J. 1995. In-Vivo Degradation and Biocompatibility Study of In-Vitro Pre-Degraded As-Polymerized Polylactide Particles. Biomaterials, 16, 267-274.

Bogaerts, A., Neyts, E., Gijbels, R. \& van der Mullen, J. 2002. Gas discharge plasmas and their applications. Spectrochimica Acta Part B-Atomic Spectroscopy, 57, 609-658.

Breulmann, M., Künkel, A., Philipp, S., Reimer, V., Siegenthaler, K. O., Skupin, G. \& Yamamoto, M. 2009. Biodegradable polymers. Ullmann's Encyclopedia of Industrial Chemistry.

Carlisle, E. S., Mariappan, M. R., Nelson, K. D., Thomes, B. E., Timmons, R. B., Constantinescu, A., Eberhart, R. C. \& Bankey, P. E. 2000. Enhancing hepatocyte adhesion by pulsed plasma deposition and polyethylene glycol coupling. Tissue Engineering, 6, 45-52.

Chen, V. J. \& Ma, P. X. 2004. Nano-fibrous poly(L-lactic acid) scaffolds with interconnected spherical macropores. Biomaterials, 25, 2065-2073.

Cheng, Z. Y. \& Teoh, S. H. 2004. Surface modification of ultra thin poly (epsiloncaprolactone) films using acrylic acid and collagen. Biomaterials, 25, 1991-2001.

Chiari, C., Koller, U., Dorotka, R., Eder, C., Plasenzotti, R., Lang, S., Ambrosio, L., Tognana, E., Kon, E., Salter, D. \& Nehrer, S. 2006. A tissue engineering approach to meniscus regeneration in a sheep model. Osteoarthritis and Cartilage, 14, 10561065.

Chong, M. S. K., Lee, C. N. \& Teoh, S. H. 2007. Characterization of smooth muscle cells on poly(epsilon-caprolactone) films. Materials Science \& Engineering C-Biomimetic and Supramolecular Systems, 27, 309-312.

De Geyter, N., Morent, R., Desmet, T., Trentesaux, M., Gengembre, L., Dubruel, P., Leys, C. \& Payen, E. 2010. Plasma modification of polylactic acid in a medium pressure DBD. Surface \& Coatings Technology, 204, 3272-3279.

De Geyter, N., Morent, R. \& Leys, C. 2008. Influence of ambient conditions on the ageing behaviour of plasma-treated PET surfaces. Nuclear Instruments $\mathcal{E}$ Methods in Physics Research Section B-Beam Interactions with Materials and Atoms, 266, 30863090 . 
De Geyter, N., Morent, R., Leys, C., Gengembre, L. \& Payen, E. 2007. Treatment of polymer films with a dielectric barrier discharge in air, helium and argon at medium pressure. Surface \& Coatings Technology, 201, 7066-7075.

Denes, F. S. \& Manolache, S. 2004. Macromolecular plasma-chemistry: an emerging field of polymer science. Progress in Polymer Science, 29, 815-885.

Desai, S. M. \& Singh, R. P. 2004. Surface modification of polyethylene.

Desmet, T., Morent, R., De Geyter, N., Leys, C., Schacht, E. \& Dubruel, P. 2009. Nonthermal Plasma Technology as a Versatile Strategy for Polymeric Biomaterials Surface Modification: A Review. Biomacromolecules, 10, 2351-2378.

Ding, Z., Chen, J. N., Gao, S. Y., Chang, J. B., Zhang, J. F. \& Kang, E. T. 2004. Immobilization of chitosan onto poly-L-lactic acid film surface by plasma graft polymerization to control the morphology of fibroblast and liver cells. Biomaterials, 25, 1059-1067.

Djordjevic, I., Britcher, L. G. \& Kumar, S. 2008. Morphological and surface compositional changes in poly(lactide-co-glycolide) tissue engineering scaffolds upon radio frequency glow discharge plasma treatment. Applied Surface Science, 254, 19291935.

Donglu, S. 2010. Synthetic biodegradable polymers. Introduction to biomaterials. World Scientific Publishing Co.

Ferreira, B. M. P., Pinheiro, L. M. P., Nascente, P. A. P., Ferreira, M. J. \& Duek, E. A. R. 2009. Plasma surface treatments of poly(L-lactic acid) (PLLA) and poly(hydroxybutyrateco-hydroxyvalerate) (PHBV). Materials Science $\mathcal{E}$ Engineering C-Biomimetic and Supramolecular Systems, 29, 806-813.

Fridman, G., Friedman, G., Gutsol, A., Shekhter, A. B., Vasilets, V. N. \& Fridman, A. 2008. Applied plasma medicine. Plasma Processes and Polymers, 5, 503-533.

Fujimaki, T. 1998. Processability and properties of aliphatic polyesters, 'BIONOLLE', synthesized by polycondensation reaction. Polymer Degradation and Stability, 59, 209-214.

Gilding, D. K. \& Reed, A. M. 1979. Biodegradable Polymers for Use in Surgery Polyglycolic-Poly(Actic Acid) Homopolymers and Copolymers .1. Polymer, 20, 1459-1464.

Goddard, J. M. \& Hotchkiss, J. H. 2007. Polymer surface modification for the attachment of bioactive compounds. Progress in Polymer Science, 32, 698-725.

Gomathi, N., Sureshkumar, A. \& Neogi, S. 2008. RF plasma-treated polymers for biomedical applications. Current Science, 94, 1478-1486.

Guerrouani, N., Baldo, A., Bouffin, A., Drakides, C., Guimon, M. F. \& Mas, A. 2007. Allylamine plasma-polymerization on PLLA surface evaluation of the biodegradation. Journal of Applied Polymer Science, 105, 1978-1986.

Gunatillake, P. A. \& Adhikari, R. 2003. Biodegradable synthetic polymers for tissue engineering. European Cells and Materials, 5, 1-16.

Gupta, B., Hilborn, J., Plummer, C., Bisson, I. \& Frey, P. 2002. Thermal crosslinking of collagen immobilized on poly(acrylic acid) grafted poly(ethylene terephthalate) films. Journal of Applied Polymer Science, 85, 1874-1880. 
Hasirci, N., Endogan, T., Vardar, E., Kiziltay, A. \& Hasirci, V. 2010. Effect of oxygen plasma on surface properties and biocompatibility of PLGA films. Surface and Interface Analysis, 42, 486-491.

Hasirci, V., Tezcaner, A., Hasirci, N. \& Suzer, S. 2003. Oxygen plasma modification of poly(3-hydroxybutyrate-co-3-hydroxyvalerate) film surfaces for tissue engineering purposes. Journal of Applied Polymer Science, 87, 1285-1289.

Heino, A., Naukkarinen, A., Kulju, T., Tormala, P., Pohjonen, T. \& Makela, E. A. 1996. Characteristics of poly(L-)lactic acid suture applied to fascial closure in rats. Journal of Biomedical Materials Research, 30, 187-192.

Hirotsu, T., Ketelaars, A. A. J. \& Nakayama, K. 2000a. Plasma surface treatment of PCL/PC blend sheets. Polymer Engineering and Science, 40, 2324-2331.

Hirotsu, T., Masuda, T., Matumura, Y. \& Takahashi, M. 1997. Surface effects of plasma treatments on some biodegradable polyesters. Journal of Photopolymer Science and Technology, 10, 123-128.

Hirotsu, T., Nakayama, K., Tsujisaka, T., Mas, A. \& Schue, F. 2002. Plasma surface treatments of melt-extruded sheets of poly(L-lactic acid). Polymer Engineering and Science, 42, 299-306.

Hirotsu, T., Tsujisaka, T., Masuda, T. \& Nakayama, K. 2000b. Plasma surface treatments and biodegradation of poly(butylene succinate) sheets. Journal of Applied Polymer Science, 78, 1121-1129.

Ho, M. H., Hou, L. T., Tu, C. Y., Hsieh, H. J., Lai, J. Y., Chen, W. J. \& Wang, D. M. 2006. Promotion of cell affinity of porous PLLA scaffolds by immobilization of RGD peptides via plasma treatment. Macromolecular Bioscience, 6, 90-98.

Ho, M. H., Lee, J. J., Fan, S. C., Wang, D. M., Hou, L. T., Hsieh, H. J. \& Lai, J. Y. 2007. Efficient modification on PLLA by ozone treatment for biomedical applications. Macromolecular Bioscience, 7, 467-474.

Hu, W. \& Huang, Z. M. 2010. Biocompatibility of braided poly(L-lactic acid) nanofiber wires applied as tissue sutures. Polymer International, 59, 92-99.

Ikada, Y. \& Tsuji, H. 2000. Biodegradable polyesters for medical and ecological applications. Macromolecular Rapid Communications, 21, 117-132.

Kang, I. K., Choi, S. H., Shin, D. S. \& Yoon, S. C. 2001. Surface modification of polyhydroxyalkanoate films and their interaction with human fibroblasts. International Journal of Biological Macromolecules, 28, 205-212.

Khang, G., Choee, J. H., Rhee, J. M. \& Lee, H. B. 2002. Interaction of different types of cells on physicochemically treated poly(L-lactide-co-glycolide) surfaces. Journal of Applied Polymer Science, 85, 1253-1262.

Khorasani, M. T., Mirzadeh, H. \& Irani, S. 2008. Plasma surface modification of poly (Llactic acid) and poly (lactic-co-glycolic acid) films for improvement of nerve cells adhesion. Radiation Physics and Chemistry, 77, 280-287.

Koo, G. H. \& Jang, J. 2008. Surface modification of poly(lactic acid) by UV/Ozone irradiation. Fibers and Polymers, 9, 674-678.

Kose, G. T., Ber, S., Korkusuz, F. \& Hasirci, V. 2003a. Poly(3-hydroxybutyric acid-co-3hydroxyvaleric acid) based tissue engineering matrices. Journal of Materials ScienceMaterials in Medicine, 14, 121-126. 
Kose, G. T., Kenar, H., Hasirci, N. \& Hasirci, V. 2003b. Macroporous poly(3hydroxybutyrate-co-3-hydroxyvalerate) matrices for bone tissue engineering. Biomaterials, 24, 1949-1958.

Lam, K. H., Nijenhuis, A. J., Bartels, H., Postema, A. R., Jonkman, M. F., Pennings, A. J. \& Nieuwenhuis, P. 1995. Reinforced Poly(L-Lactic Acid) Fibers As Suture Material. Journal of Applied Biomaterials, 6, 191-197.

Langmuir, I. 1928. Oscillations in ionized gases. Proceedings of the National Academy of Sciences of the United States of America, 14, 627-637.

Lee, H. U., Jeong, Y. S., Jeong, S. Y., Park, S. Y., Bae, J. S., Kim, H. G. \& Cho, C. R. 2008. Role of reactive gas in atmospheric plasma for cell attachment and proliferation on biocompatible poly epsilon-caprolactone film. Applied Surface Science, 254, 57005705.

Lee, H. U., Jeong, Y. S., Koh, K. N., Jeong, S. Y., Kim, H. G., Bae, J. S. \& Cho, C. R. 2009. Contribution of power on cell adhesion using atmospheric dielectric barrier discharge (DBD) plasma system. Current Applied Physics, 9, 219-223.

Li, G. M., Cai, Q., Bei, J. Z. \& Wang, S. G. 2002. Relationship between morphology structure and composition of polycaprolactone/poly (ethylene oxide)/polylactide copolymeric microspheres. Polymers for Advanced Technologies, 13, 636-643.

Li, G. M., Cai, Q., Bei, J. Z. \& Wang, S. G. 2003. Morphology and levonorgestrel release behavior of polycaprolactone/poly(ethylene oxide)/polylactide tri-component copolymeric microspheres. Polymers for Advanced Technologies, 14, 239-244.

Li, H. Y., Chang, J., Cao, A. M. \& Wang, J. Y. 2005. In vitro evaluation of biodegradable poly(butylene succinate) as a novel biomaterial. Macromolecular Bioscience, 5, 433440.

Lieberman, M. A. \& Lichtenberg, A. J. 2005. Principles of plasma discharges and materials processing - Second edition, Hoboken, New Jersey, John Wiley \& Sons, Inc.

Little, U., Buchanan, F., Harkin-Jones, E., Graham, B., Fox, B., Boyd, A., Meenan, B. \& Dickson, G. 2009. Surface modification of poly(epsilon-caprolactone) using a dielectric barrier discharge in atmospheric pressure glow discharge mode. Acta Biomaterialia, 5, 2025-2032.

Loo, S. C. J., Ooi, C. P. \& Boey, Y. C. F. 2004. Radiation effects on poly(lactide-co-glycolide) (PLGA) and poly(L-lactide) (PLLA). Polymer Degradation and Stability, 83, 259-265.

Ma, P. X., Xiaohua, L. \& Youngjun, W. 2006. Porogen-induced surface modification of nano-fibrous poly(l-lactic acid) scaffolds for tissue engineering. Biomaterials, vol.27, no.21, 3980-3987.

Ma, Z. W., Mao, Z. W. \& Gao, C. Y. 2007. Surface modification and property analysis of biomedical polymers used for tissue engineering. Colloids and Surfaces BBiointerfaces, 60, 137-157.

Maurus, P. B. \& Kaeding, C. C. 2004. Bioabsorbable implant material review. Operative Techniques in Sports Medicine, 12, 158-160.

Middleton, J. C. \& Tipton, A. J. 2000. Synthetic biodegradable polymers as orthopedic devices. Biomaterials, 21, 2335-2346. 
Miller, R. A., Brady, J. M. \& Cutright, D. E. 1977. Degradation Rates of Oral Resorbable Implants (Polylactates and Polyglycolates) - Rate Modification with Changes in Pla-Pga Copolymer Ratios. Journal of Biomedical Materials Research, 11, 711-719.

Mondrinos, M. J., Dembzynski, R., Lu, L., Byrapogu, V. K. C., Wootton, D. M., Lelkes, P. I. \& Zhou, J. 2006. Porogen-based solid freeform fabrication of polycaprolactonecalcium phosphate scaffolds for tissue engineering. Biomaterials, 27, 4399-4408.

Montanari, L., Costantini, M., Signoretti, E. C., Valvo, L., Santucci, M., Bartolomei, M., Fattibene, P., Onori, S., Faucitano, A., Conti, B. \& Genta, I. 1998. Gamma irradiation effects on poly(DL-lactictide-co-glycolide) microspheres. Journal of Controlled Release, 56, 219-229.

Morent, R., De Geyter, N., Desmet, T., Dubruel, P. \& Leys, C. 2011. Plasma Surface Modification of Biodegradable Polymers: A Review. Plasma Processes and Polymers, 8, 171-190.

Morent, R., De Geyter, N., Gengembre, L., Leys, C., Payen, E., Van Vlierberghe, S. \& Schacht, E. 2008a. Surface treatment of a polypropylene film with a nitrogen DBD at medium pressure. European Physical Journal-Applied Physics, 43, 289-294.

Morent, R., De Geyter, N. \& Leys, C. 2008b. Effects of operating parameters on plasmainduced PET surface treatment. Nuclear Instruments $\mathcal{E}$ Methods in Physics Research Section B-Beam Interactions with Materials and Atoms, 266, 3081-3085.

Morent, R., De Geyter, N., Trentesaux, M., Gengembre, L., Dubruel, P., Leys, C. \& Payen, E. 2010. Influence of Discharge Atmosphere on the Ageing Behaviour of PlasmaTreated Polylactic Acid. Plasma Chemistry and Plasma Processing, 30, 525-536.

Morent, R., De Geyter, N., Van Vlierberghe, S., Dubruel, P., Leys, C., Gengembre, L., Schacht, E. \& Payen, E. 2009. Deposition of HMDSO-based coatings on PET substrates using an atmospheric pressure dielectric barrier discharge. Progress in Organic Coatings, 64, 304-310.

Nair, L. S. \& Laurencin, C. T. 2007. Biodegradable polymers as biomaterials. Progress in Polymer Science, 32, 762-798.

Ojumu, T. V., Yu, J. \& Solomon, B. O. 2004. Production of Polyhydroxyalkanoates, a bacterial biodegradable polymer. African journal of Biotechnology, 3, 18-24.

Park, H., Lee, J. W., Park, K. E., Park, W. H. \& Lee, K. Y. 2010. Stress response of fibroblasts adherent to the surface of plasma-treated poly(lactic-co-glycolic acid) nanofiber matrices. Colloids and Surfaces B-Biointerfaces, 77, 90-95.

Park, K. E., Lee, K. Y., Lee, S. J. \& Park, W. H. 2007. Surface characteristics of plasmatreated PLGA nanofibers. Macromolecular Symposia, 249, 103-108.

Place, E. S., George, J. H., Williams, C. K. \& Stevens, M. M. 2009. Synthetic polymer scaffolds for tissue engineering. Chemical Society Reviews, 38, 1139-1151.

Pompe, T., Keller, K., Mothes, G., Nitschke, M., Teese, M., Zimmermann, R. \& Werner, C. 2007. Surface modification of poly(hydroxybutyrate) films to control cell-matrix adhesion. Biomaterials, 28, 28-37.

Prabhakaran, M. P., Venugopal, J., Chan, C. K. \& Ramakrishna, S. 2008. Surface modified electrospun nanofibrous scaffolds for nerve tissue engineering. Nanotechnology, 19. 
Qian, H. T., Bei, J. Z. \& Wang, S. G. 2000. Synthesis, characterization and degradation of ABA block copolymer of L-lactide and epsilon-caprolactone. Polymer Degradation and Stability, 68, 423-429.

Ramchandani, M. \& Robinson, D. 1998. In vitro and in vivo release of ciprofloxacin from PLGA 50 : 50 implants. Journal of Controlled Release, 54, 167-175.

Rasal, R. M., Janorkar, A. V. \& Hirt, D. E. 2010. Poly(lactic acid) modifications. Progress in Polymer Science, 35, 338-356.

Rausher, H., Perucca, M. \& Buyle, G. 2010. Plasma Technology for hyperfunctional surfaces, Weinheim, Wiley-VCH Verlag $\mathrm{GmbH} \& \mathrm{Co}$.

Reed, A. M. \& Gilding, D. K. 1981. Biodegradable Polymers for Use in Surgery Poly(Glycolic)-Poly(Lactic Acid) Homo and Co-Polymers .2. Invitro Degradation. Polymer, 22, 494-498.

Ryu, G. H., Yang, W. S., Roh, H. W., Lee, I. S., Kim, J. K., Lee, G. H., Lee, D. H., Park, B. J., Lee, M. S. \& Park, J. C. 2005. Plasma surface modification of poly(D,L-lactic-coglycolic acid)(65/35) film for tissue engineering. Surface \& Coatings Technology, 193, 60-64.

Safinia, L., Wilson, K., Mantalaris, A. \& Bismarck, A. 2007. Atmospheric plasma treatment of porous polymer constructs for tissue engineering applications. Macromolecular Bioscience, 7, 315-327.

Safinia, L., Wilson, K., Mantalaris, A. \& Bismarck, A. 2008. Through-thickness plasma modification of biodegradable and nonbiodegradable porous polymer constructs. Journal of Biomedical Materials Research Part A, 87A, 632-642.

Shelton, J. R., Lando, J. B. \& Agostini, D. E. 1971. Synthesis and Characterization of Poly (Beta-Hydroxybutyrate). Journal of Polymer Science Part B-Polymer Letters, 9, 173- \& .

Shen, H., Hu, X. X., Bei, J. Z. \& Wang, S. G. 2008. The immobilization of basic fibroblast growth factor on plasma-treated poly(lactide-co-glycolide). Biomaterials, 29, 23882399.

Shen, H., Hu, X. X., Yang, F., Bel, J. Z. \& Wang, S. G. 2007. Combining oxygen plasma treatment with anchorage of cationized gelatin for enhancing cell affinity of poly(lactide-co-glycolide). Biomaterials, 28, 4219-4230.

Siow, K. S., Britcher, L., Kumar, S. \& Griesser, H. J. 2006. Plasma methods for the generation of chemically reactive surfaces for biomolecule immobilization and cell colonization - A review. Plasma Processes and Polymers, 3, 392-418.

Storey, R. F. \& Taylor, A. E. 1998. Effect of stannous octoate on the composition, molecular weight, and molecular weight distribution of ethylene glycol-initiated poly(epsilon-caprolaccone). Journal of Macromolecular Science-Pure and Applied Chemistry, A35, 723-750.

Taylor, M. S., Daniels, A. U., Andriano, K. P. \& Heller, J. 1994. 6 Bioabsorbable Polymers In-Vitro Acute Toxicity of Accumulated Degradation Products. Journal of Applied Biomaterials, 5, 151-157.

Tezcaner, A., Bugra, K. \& Hasirci, V. 2003. Retinal pigment epithelium cell culture on surface modified poly(hydroxybutyrate-co-hydroxyvalerate) thin films. Biomaterials, 24, 4573-4583. 
Tserki, V., Matzinos, P., Pavlidou, E., Vachliotis, D. \& Panayiotou, C. 2006. Biodegradable aliphatic polyesters. Part I. Properties and biodegradation of poly(butylene succinate-co-butylene adipate). Polymer Degradation and Stability, 91, 367-376.

Vaquette, C., Frochot, C., Rahouadj, R. \& Wang, X. 2008. An innovative method to obtain porous PLLA scaffolds with highly spherical and interconnected pores. Journal of Biomedical Materials Research Part B-Applied Biomaterials, 86B, 9-17.

Vasilets, V. N., Hermel, G., Konig, U., Werner, C., Muller, M., Simon, F., Grundke, K., Ikada, Y. \& Jacobasch, H. J. 1997. Microwave CO2 plasma-initiated vapour phase graft polymerization of acrylic acid onto polytetrafluoroethylene for immobilization of human thrombomodulin. Biomaterials, 18, 1139-1145.

Vroman, I. \& Tighzert, L. 2009. Biodegradable polymers. Materials, 2, 307-344.

Wan, Y. Q., Tu, C. F., Yang, J. A., Bei, J. Z. \& Wang, S. G. 2006. Influences of ammonia plasma treatment on modifying depth and degradation of poly(L-lactide) scaffolds. Biomaterials, 27, 2699-2704.

Wang, E. A., Rosen, V., Dalessandro, J. S., Bauduy, M., Cordes, P., Harada, T., Israel, D. I., Hewick, R. M., Kerns, K. M., Lapan, P., Luxenberg, D. P., McQuaid, D., Moutsatsos, I. K., Nove, J. \& Wozney, J. M. 1990. Recombinant Human Bone Morphogenetic Protein Induces Bone-Formation. Proceedings of the National Academy of Sciences of the United States of America, 87, 2220-2224.

Wang, S. G., Chen, H. L., Cai, Q. \& Bei, J. Z. 2001. Degradation and 5-fluorouracil release behavior in vitro of polycaprolactone/poly(ethylene oxide)/polylactide tricomponent copolymer. Polymers for Advanced Technologies, 12, 253-258.

Wang, Y. J., Lu, L., Zheng, Y. D. \& Chen, X. F. 2006. Improvement in hydrophilicity of PHBV films by plasma treatment. Journal of Biomedical Materials Research Part A, 76A, 589-595.

Wang, Y. Q., Qu, X., Lu, J., Zhu, C. F., Wan, L. J., Yang, J. L., Bei, J. Z. \& Wang, S. G. 2004. Characterization of surface property of poly(lactide-co-glycolide) after oxygen plasma treatment. Biomaterials, 25, 4777-4783.

Xie, Z. W. \& Buschle-Diller, G. 2010. Electrospun Poly(D,L-lactide) Fibers for Drug Delivery: The Influence of Cosolvent and the Mechanism of Drug Release. Journal of Applied Polymer Science, 115, 1-8.

Yang, J., Bei, J. Z. \& Wang, S. G. 2002. Enhanced cell affinity of poly (D,L-lactide) by combining plasma treatment with collagen anchorage. Biomaterials, 23, 2607-2614.

Yildirim, E. D., Ayan, H., Vasilets, V. N., Fridman, A., Guceri, S. \& Sun, W. 2008. Effect of dielectric barrier discharge plasma on the attachment and proliferation of osteoblasts cultured over poly(epsilon-caprolactone) scaffolds. Plasma Processes and Polymers, 5, 58-66.

Zelzer, M., Scurr, D., Abdullah, B., Urquhart, A. J., Gadegaard, N., Bradley, J. W. \& Alexander, M. R. 2009. Influence of the Plasma Sheath on Plasma Polymer Deposition in Advance of a Mask and down Pores. Journal of Physical Chemistry B, $113,8487-8494$.

Zhu, L. P., Zhu, B. K., Xu, L., Feng, Y. X., Liu, F. \& Xu, Y. Y. 2007. Corona-induced graft polymerization for surface modification of porous polyethersulfone membranes. Applied Surface Science, 253, 6052-6059. 
Zhu, Y. B., Gao, C. Y., Liu, X. Y. \& Shen, J. C. 2002. Surface modification of polycaprolactone membrane via aminolysis and biomacromolecule immobilization for promoting cytocompatibility of human endothelial cells. Biomacromolecules, 3, 1312-1319.

Zhu, Y. B., Gao, C. Y., Liu, Y. X. \& Shen, J. C. 2004. Endothelial cell functions in vitro cultured on poly(L-lactic acid) membranes modified with different methods. Journal of Biomedical Materials Research Part A, 69A, 436-443. 


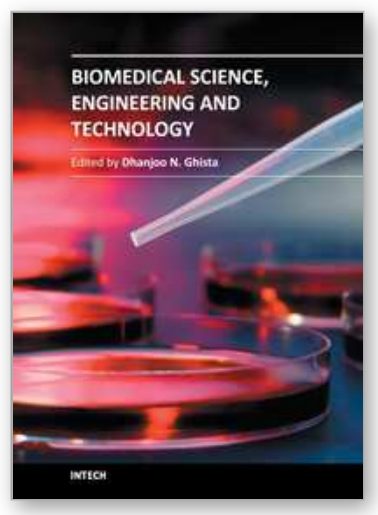

\author{
Biomedical Science, Engineering and Technology \\ Edited by Prof. Dhanjoo N. Ghista
}

ISBN 978-953-307-471-9

Hard cover, 902 pages

Publisher InTech

Published online 20, January, 2012

Published in print edition January, 2012

This innovative book integrates the disciplines of biomedical science, biomedical engineering, biotechnology, physiological engineering, and hospital management technology. Herein, Biomedical science covers topics on disease pathways, models and treatment mechanisms, and the roles of red palm oil and phytomedicinal plants in reducing HIV and diabetes complications by enhancing antioxidant activity. Biomedical engineering coves topics of biomaterials (biodegradable polymers and magnetic nanomaterials), coronary stents, contact lenses, modelling of flows through tubes of varying cross-section, heart rate variability analysis of diabetic neuropathy, and EEG analysis in brain function assessment. Biotechnology covers the topics of hydrophobic interaction chromatography, protein scaffolds engineering, liposomes for construction of vaccines, induced pluripotent stem cells to fix genetic diseases by regenerative approaches, polymeric drug conjugates for improving the efficacy of anticancer drugs, and genetic modification of animals for agricultural use. Physiological engineering deals with mathematical modelling of physiological (cardiac, lung ventilation, glucose regulation) systems and formulation of indices for medical assessment (such as cardiac contractility, lung disease status, and diabetes risk). Finally, Hospital management science and technology involves the application of both biomedical engineering and industrial engineering for cost-effective operation of a hospital.

\title{
How to reference
}

In order to correctly reference this scholarly work, feel free to copy and paste the following:

N. De Geyter and R. Morent (2012). Non-Thermal Plasma Surface Modification of Biodegradable Polymers, Biomedical Science, Engineering and Technology, Prof. Dhanjoo N. Ghista (Ed.), ISBN: 978-953-307-471-9, InTech, Available from: http://www.intechopen.com/books/biomedical-science-engineering-andtechnology/non-thermal-plasma-surface-modification-of-biodegradable-polymers

\section{INTECH}

open science | open minds

\author{
InTech Europe \\ University Campus STeP Ri \\ Slavka Krautzeka 83/A \\ 51000 Rijeka, Croatia \\ Phone: +385 (51) 770447 \\ Fax: +385 (51) 686166 \\ www.intechopen.com
}

\author{
InTech China \\ Unit 405, Office Block, Hotel Equatorial Shanghai \\ No.65, Yan An Road (West), Shanghai, 200040, China \\ 中国上海市延安西路65号上海国际贵都大饭店办公楼 405 单元 \\ Phone: +86-21-62489820 \\ Fax: +86-21-62489821
}


(C) 2012 The Author(s). Licensee IntechOpen. This is an open access article distributed under the terms of the Creative Commons Attribution 3.0 License, which permits unrestricted use, distribution, and reproduction in any medium, provided the original work is properly cited. 